\title{
Growth and characterization of organic layers deposited on porous-patterned Si surface
}

\author{
Tamara Ya. Gorbach ${ }^{1}$, Petro S. Smertenko ${ }^{1}$, G.P. Olkhovik ${ }^{1}$, Grzegorz Wisz ${ }^{2}$ \\ ${ }^{1}$ V.Lashkarev Institute of Semiconductors Physics, NAS of Ukraine, 45, Prospekt Nauki, 03028, Kyiv, \\ Ukraine \\ ${ }^{2}$ Chair of Experimental Physics, Faculty of Mathematics and Natural Sciences , University of Rzeszow, \\ S. Pigonia 1, 35-959 Rzeszow, Poland
}

\begin{abstract}
The organic layers with the thickness from a few nanometers up to few micrometers have been deposited from the chemical solution at room temperature on porous patterned $\mathrm{Si}$ surfaces using two medical solutions: thiamine diphosphide $(\mathrm{pH}=1 \div 2)$ and metamizole sodium $(\mathrm{pH}=6 \div 7)$. Based on evolution of morphology, structural and compositional features obtained by scanning electron microscopy, X-ray analysis, reflectance high energy electron diffraction the grown mechanisms in thin organic layers are discussed in the terms of terrace-step-kink model whereas self-organized assemblies evaluated more thick layers. Transport mechanism features and possible photovoltaic properties are discussed on the base of differential current-voltage characteristics.
\end{abstract}

\section{Introduction}

Organic materials - pigments, dyes, polymers and their combination with the typical inorganic ones such as metals, metal oxides, semitransparent or semiconductor substrates have been intensively investigated over the last decades []. Currently hybrid organicinorganic nanocomposites are considered as materials being suitable for a wide range of applications [1]. The electroluminescent devices [2-4], thin field effect transistors [5, 6], solar cells [7- 11], etc. were prepared, characterized and reported. Due to the nanosized molecules of organic materials as well as the lowdimensional semiconductor systems the novel and the special properties of thin organic layers and hybrid formations are observed. They are proposed as the next generation for electronics devices and potential candidates for practical application in different fields of electronics, optoelectronics, photovoltaics, biosensors, biomedicine, etc.

Various technological methods such as thermal or laser evaporation, chemical vapor deposition, chemical solution growth, spin coating and many others were developed for preparing the active organic multilayer. Information about growth mechanisms, surface and interface morphology, crystalline structure, chemistry, composition of thin layer is prerequisite to understand and fabricate their precise and desirable properties. In our previous work [12] it was shown that improvement of initial $\mathrm{Si}$-based solar cell with EFF less that $7 \%$ up to $15 \%$ can take place by treatment in organic solutions. As organic materials the medical preparations were chosen. The $\mathrm{Si} n^{+} p$ 
patterned solar cells were the waster of technology taking place in photovoltaics.

This paper presents some experimental data on the porous patterned $\mathrm{Si}$ structures stimulated still much investigation for application in optoelectronics and photovoltaics.

\section{Experimental}

The deposition of organic layers onto porous patterned $S i$ substrate was carried out from aqueous solution of thiamine diphosphide (TD) and metamizole sodium (MS) at room temperature during $100 \mathrm{~min}$ and 20 hours. These organic materials are medical ones. They were deposited onto $\mathrm{Si}$ surface without preliminary purification. The molecular structure of organic medical material is shown in Fig.1.

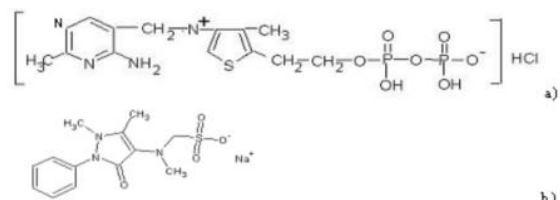

Fig. 1. Molecular structure of the organic materials: a) - thiamine diphosphide, contained $H, C, N, O, S, P, C l$ elements; b) - metamizole sodium, contained $H, C, N, O, S, N a$ elements.

According to chemical formula the first material contains $\mathrm{H}, \mathrm{C}, \mathrm{N}, \mathrm{O}, \mathrm{S}, \mathrm{P}, \mathrm{Cl}$ elements, has an acid chemistry $(\mathrm{pH}=1 \pm 2)$. It is known in medicine as cocarboxylase hydrochloride. The second one has alcaline chemistry $(\mathrm{pH}=6 \pm 7)$, contains $H$, $C, N, O, S, N a$ elements and named analgin.

The porous $\mathrm{Si}$ was formed by electrochemical etching (ECE) in $\mathrm{HF}: \mathrm{C}_{3} \mathrm{H}_{7} \mathrm{OH}=1: 1$ electrolyte at current density $10-30-\mathrm{mA} / \mathrm{cm}^{2}$ on patterned pyramid $S i$ like surface. The last was produced on $\{100\}$ cutting, $10 \Omega \mathrm{cm}$ resistivity, B-doped CZ-Si wafers with thickness $300 \mu \mathrm{m}$ by anisotropic chemical etching (ACE) in $10 \% \mathrm{KOH}$ at room temperature during some minutes. Patterned porous surface has average pyramid dimension of $2-3 \mu \mathrm{m}$ at the base and $1.5-2 \mu \mathrm{m}$ in the height with the thickness of porous layer is about $0.2-0.3$ $\mu \mathrm{m}$.

Superprobe microanalyzer JXA-733 and optical microscopy were used to obtain information about morphology features, composition and growth mechanisms of deposited layers. The layer crystallinity was characterised by reflection high-energy electron difraction (RHEED) with electron microscopy JEM$6 \mathrm{~A}$.

The current-voltage characteristics (I-VC) were measured in In-organic-PS$\mathrm{Si}-\mathrm{In}$ sandwich systems in the dark and under illumination in both directions using automated tester 14 TKS-100 (USSR). For illumination the Xenon lamp was used with intensity equivalent 0.03 sun. Analysis of $I-V$ characteristics of hybrids in the terms of differential slope $\alpha=$ $d \log I / d \log V$ was carried out $[13,14]$.

\section{Results and discussion}

\subsection{Morphology}

The typical morphology fragments of layers deposited from TD and MS solutions are presented in (Fig. 2 a, c-e) and (Fig.2 f-h), respectively. Fig. 2b shows RHEED pattern observed after layer deposition from TD solution during 100 min. As seen from Fig.2 there are no significant effect on organic layer morphology formed from solution with different chemistry. On early stage formation the layer contour is the same as the substrate one. There is the morphological stability condition during growth process. Due to excellent morphological feature of facet $\{111\}$ which is a vicinal surface and contains a quasiperiodic flat low-Miller- index terraces separated by steps with kinks the surface midiated heteroepitaxy take place. 




Fig. 2.a

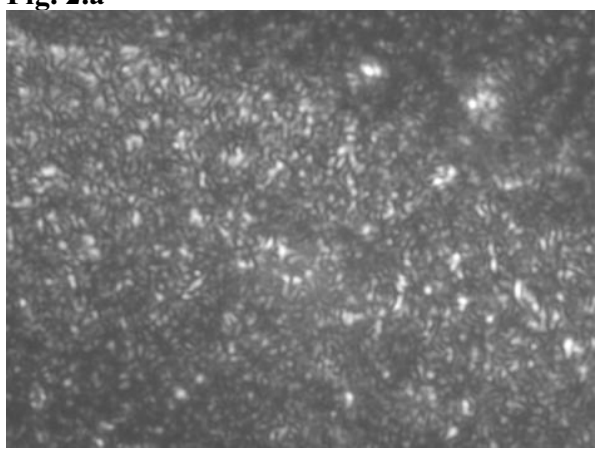

Fig. 2.c

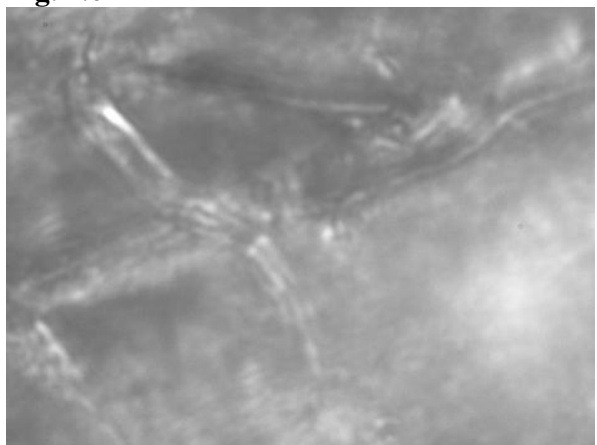

Fig. 2.e

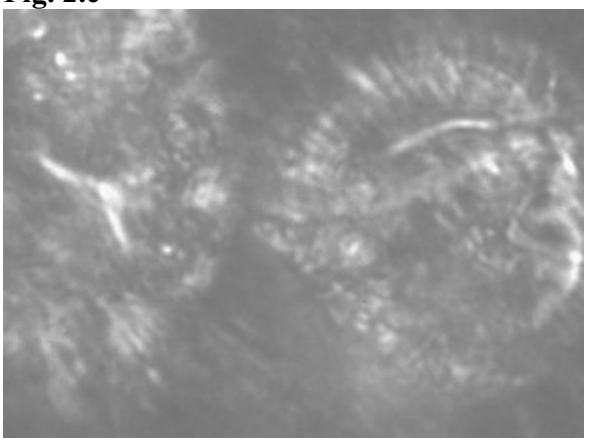

Fig. 2.g

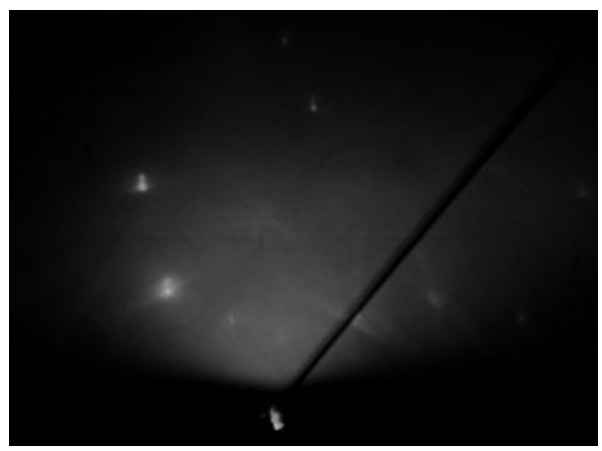

Fig. 2.b

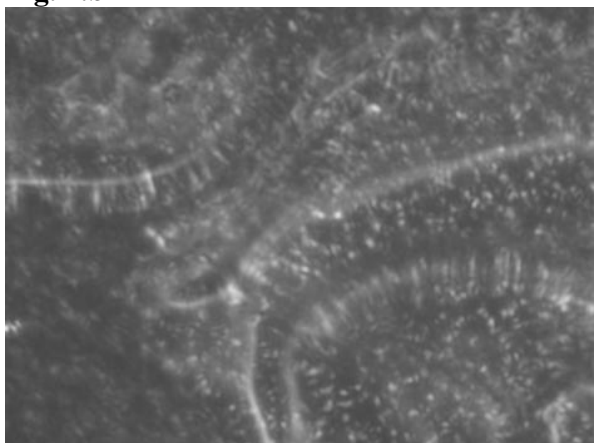

Fig. 2.d

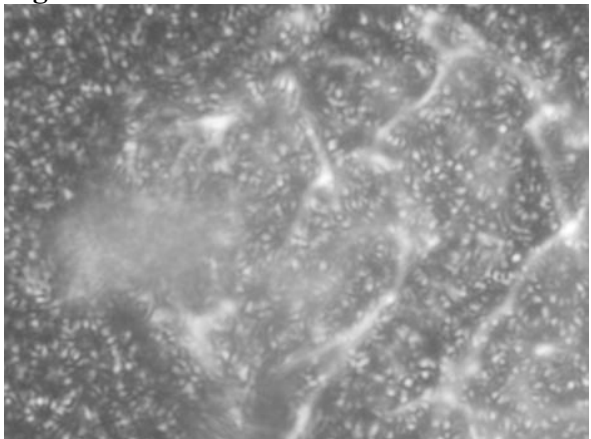

Fig. 2.f

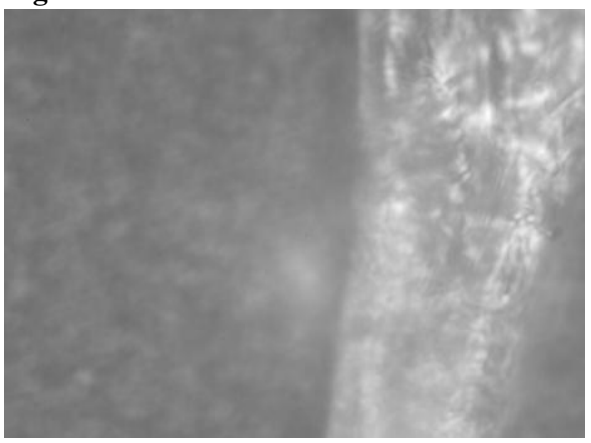

Fig. 2.h

Fig. 2. a, b - morphology and RHEED pattern of layer deposited from TD solution during $100 \mathrm{~min}$; c-e and $\mathbf{f}-\mathbf{h}$ - morphology of layers deposited from TD and MS solution during $20 \mathrm{H}$, respectively. 
In such case a low temperature and even room temperature deposition of good quality layer is possible in spite of the factor of the big lattice mismatch and difference in the thermal expansion coefficient [15]. The scale of the roughness prepared by ECE is essentially less than TSK feature size. That is why the TSK growth model is realized. The RHEED observation (Fig.2b) shows the spots and Kikuchi lines. In this RHEED pattern the high quality heteroepitaxy is testified.

With deposition time increasing till 20 hours the loss stability conditions take place and complex morphologies are grown in circular, square and rhombic forms. These forms include mostly filaments and dots (Fig. 2 d-h). However these formations are not only due to selforganisation. In this case the substrate pre-pattern determines their further development too.

According to X-ray analysis the both deposited layers exhibit the same components as solution. Because TD contains often $\mathrm{K}, \mathrm{Na}, \mathrm{Ca}, \mathrm{Mg}$ ligands the $\mathrm{X}$-ray analysis of thin layers was shown the presence of $\mathrm{Ca}$ content and $\mathrm{Na}$ element in thick layers. These elements are absent in molecular formula (Fig.1a).
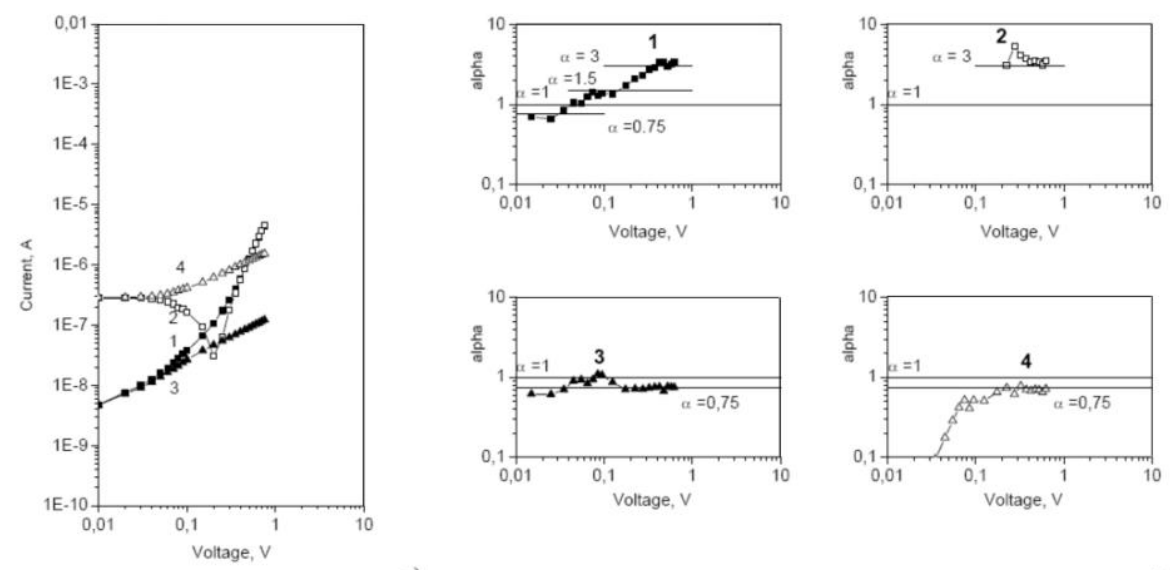

a)

b)
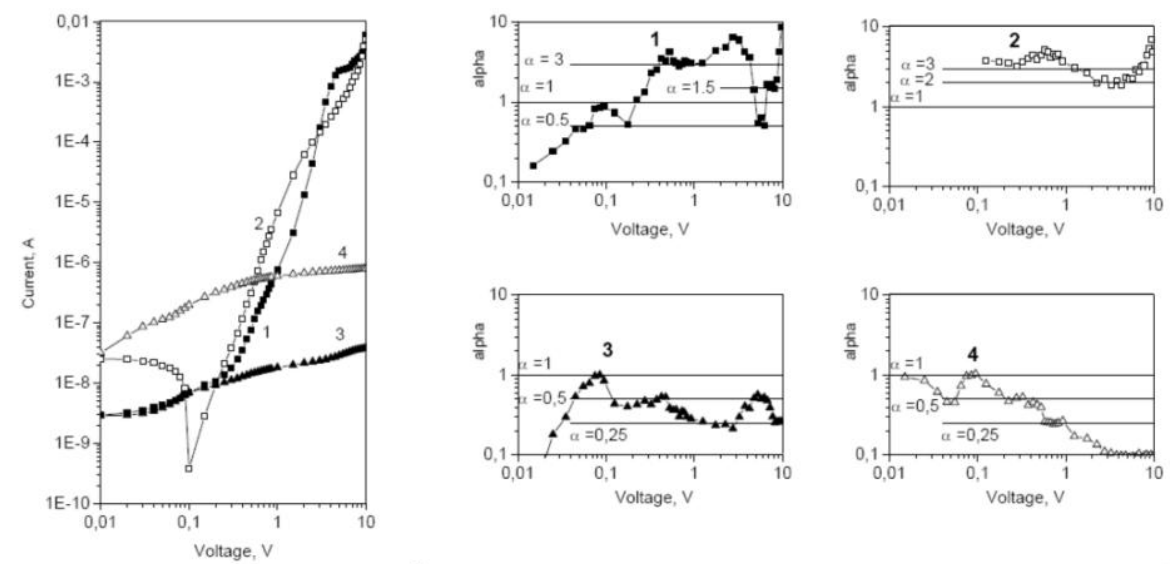

c)

d)

Fig. 3. Current-voltage characteristics a), c) and their differential image b), d) for the layers deposited from TD during 100 min $-\mathrm{a}$ ), b) and during 20 hours - c), d); curve 1 forward dark, curve 2 forward under illumination, curve 3 reverse dark and curve 4 reverse under illumination. 


\subsection{Current-voltage characteristics}

The current-voltage characteristics of the structures under investigation and their differential image are shown in Fig. 3 and Fig.4 for TD and MS solutions, respectively. The main feature of all I-VC is the wide variety of differential slope: from sub-linear behaviour with $\alpha=0.1$ (Fig. $3 \mathrm{~d}$ curve 4 ); $\alpha=0.25$ (Fig. $3 \mathrm{~d}$ curves 3 , 4); $\alpha=0.5$ (Fig.3d curves 1, 3, 4); $\alpha=0.75$ (Fig.3b curves 1, 3, 4; Fig.4d curves 3, 4); to super-linear one with $\alpha=1.5$ (Fig.3b curve 1; Fig.3d curve 1; Fig.4b curves 3, 4; Fig.4d curves 1, 2, 3); $\alpha=2.0$ (Fig.3d curve 2; Fig.4b curves 1, 2, 3; Fig.4d curves $1,2,3,4$ ); $\alpha=3.0$ (Fig.3b curves 1 , 2; Fig.3d curves 1, 2; Fig.4b curves 1, 2; Fig.4d curves 1,2).

Some of such behaviour is well known from literature [16-19]: $\alpha=3.0$ corresponds to the high injection of charge carriers into dielectric; $\alpha=2.0$ can be referred to the space charge limited currents or to the double injection under monomolecular recombination of charge carriers with predominance of only one charge carriers type, whereas $\alpha=1.5$ is occur under bimolecular recombination of charge carriers with approximately equal quantity of both charge carriers types. The unusual behaviour with $\alpha=0.25$ and $\alpha=0.75$ we can see for reverse direction for both structures. It can be explained on the base of general speculation that some additive process with law $\mathrm{I} \sim \mathrm{V}^{0.25}$ influences the IVC. For Ohm law such influence gives $\alpha=0.75$ or 1.25 . It modifies the rectification behaviour with $\alpha=0.5$ to $\alpha=0.25$ or $\alpha=0.75$. The I-VC with $\alpha=1.25$ was reported for some organic and amorphous materials [14,20].
It is necessary to note also the other features of the structures under investigation:

1. Asymmetric characteristic for TD solution. The ratio of forward to reverse currents is about 40 at $\mathrm{V}=0.75 \mathrm{~V}$ for the layer under deposition during $100 \mathrm{~min}$ in TD solution. It decreases to 6 under deposition during 20 hours. To check the exponential behaviour the following procedure on the base of differential approach [14] was used. For usual exponential law for diode we have $\mathrm{I} \sim \exp \{\mathrm{eV} / \mathrm{nkT}\}$, where $\mathrm{e}$ is the electron charge, $\mathrm{k}$ is the Boltzman constant, $\mathrm{T}$ is absolute temperature and $\mathrm{n}$ is the nonideality coefficient. In this case the differential slope $\alpha=\mathrm{eV} / \mathrm{nkT}$ and at $\mathrm{V}=0$ $\alpha=0$ (Fig, 5b, curve 1, $\alpha_{2}=19 * \mathrm{~V}$ ) and estimation for nonideality coefficient gives $\mathrm{n}=2$. The second range of experimental curve can be approximated by equation $\alpha_{1}=6.3(\mathrm{~V}+0.1)$. For $\mathrm{I}-\mathrm{VC}$ it gives after integration: $\mathrm{I}=\mathrm{AV}^{\mathrm{b}} * \exp (\mathrm{BV}) \quad$ with $\mathrm{A}=8 * 10^{-8} ; \mathrm{b}=0.63 ; \mathrm{B}=6.3$. Comparison of this approximation with experimental data is presented in Fig.5a and b.

The I-CV is described by exponent enough well in all voltage range, but the differential slope shows that after $0.4 \mathrm{~V}$ the behaviour is not exponential and $\alpha=3$.

2. The photosensitivity of the layers deposited from TD and MS solutions. The sensitivity of structures with TD is higher than with MS and in both cases it decreases with increase of layer thickness.

3. Photovoltaic properties for TD solution. The increase of the layer thickness leads to decrease of open circuit voltage and short circuit current. 

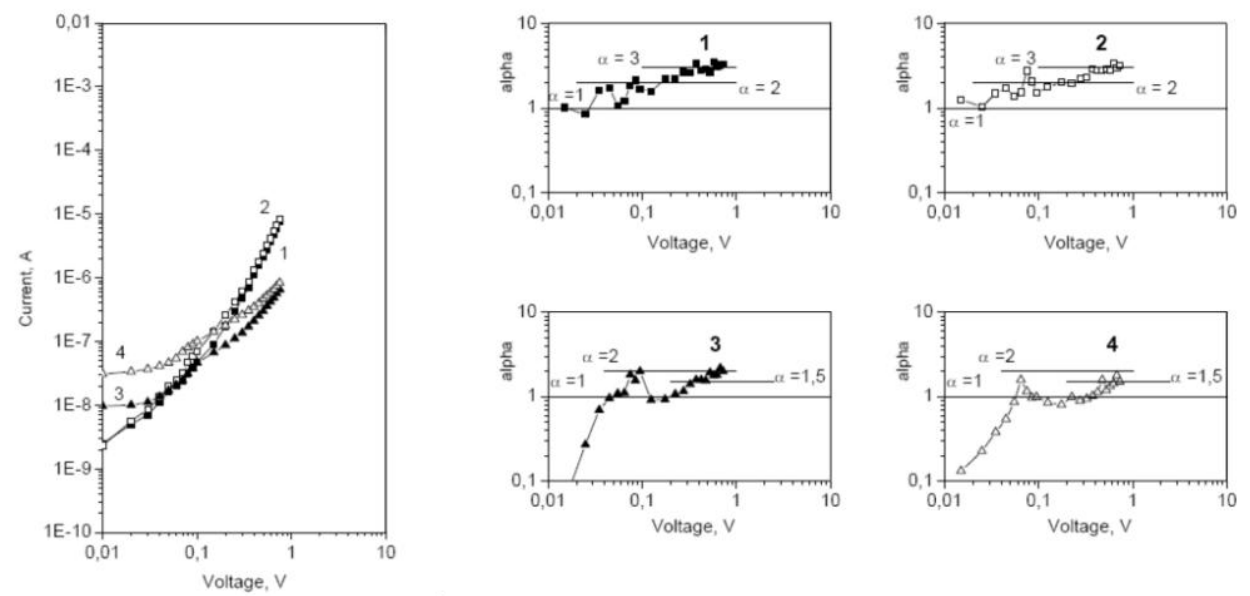

a)

b)
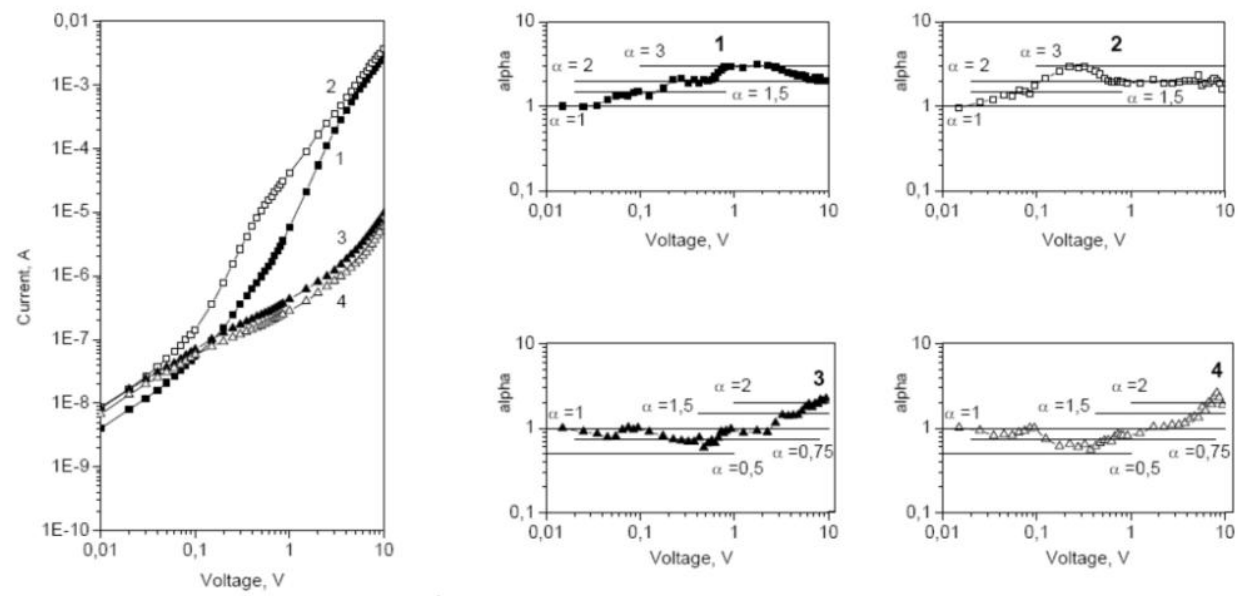

c)

Fig. 4. Current-voltage characteristics a), c) and their differential image b), d) for the layers deposited from MS during $100 \mathrm{~min}-\mathrm{a}$ ), b) and during 20 hours $-\mathrm{c}$ ), d); curve 1 forward dark, curve 2 forward under illumination, curve 3 reverse dark and curve 4 reverse under illumination. 

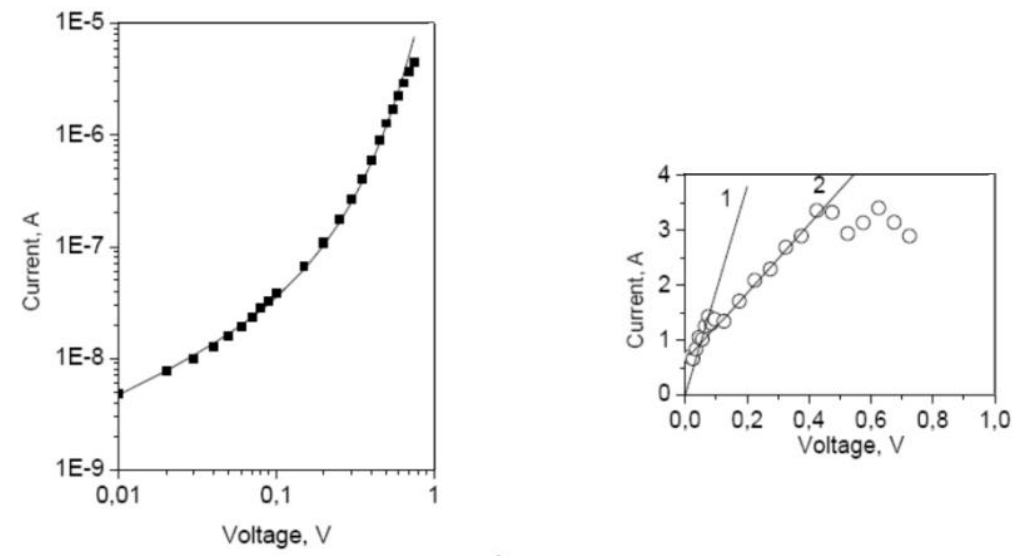

a)

Fig. 5. Modelling of current-voltage characteristic a) and their differential image b) for the layer deposited from TD during 100 min, curve 1 forward dark. Solid curve in a) corresponds to equation: $I=\mathrm{A} V^{\mathrm{b}} \cdot \exp (\mathrm{B} V)$ with $\mathrm{A}=8 \cdot 10^{-8} ; \mathrm{b}=0.63 ; \mathrm{B}=6.3$. Solid curves 1 and 2 in $\left.\mathrm{b}\right)$ correspond to equations $\alpha_{1}=19 \cdot V$ and $\alpha_{2}=6.3(V+0.1)$, respectively.

\section{Conclusions}

1. Organic layers deposited at room temperature from aqueous solution of medical materials of thiamine diphosphide and metamizole sodium modified the morphology, chemical composition and physical properties of porous patterned substrates. This modification do not depend on solution chemistry and is determined by deposition time, i.e. layer thickness. For thin organic layers $(\leq 100 \mu \mathrm{m})$ the layer contour is the same as substrate and terrace-step-kink growth mechanism is realized. For more thick layers (up to micrometer) self-organized assemblies are formed but with preference of pre-pattern substrate.

2. On the interface of TD layer - porous patterned substrate the barrier is formed and PV characteristic is observed.

3. In the TD (MS) layer - porous patterned system the transport is determined some processes but mainly the high injection of charge carriers in dielectric organic layers.
4. Chemical solution deposition at room temperature is newly simple technological process useful for realization of hybrid organic-inorganic structures.

\section{References}

1. Milliron D. J., Gur I., Alivisatos A. P. MRS Bull. 30, 41-44 (2005)

2. Kyu-Seong Hwang, Ju-Hyun Jeong, Kyung-OK Jeon, Young-Sun Jeon, Byung-Hoon Kim. Ceramics International 33, 6, 1071-1074 (2007)

3. Gunes S., Sariciftci N.S. Inorg. Chem. Acta 361, 581-585 (2008)

4. T. W. Baehr-Jones and M. J. Hochberg. J. Phys. Chem. C 112 (21), 8085-8090 (2008)

5. Tao F. Bernasek, S.L. Xu Guo-Quin, Chem. Rev. 109, 3991-4024 (2009)

6. H. Ma, H.-L. Yip, F. Huang et al., Adv. Funct. Mater. 20, 9, 1371-1388 (2010)

7. S. Wie, Q. Wang, J. Zhu et al. Nanoscale 3, 4474-4502 (2011) 
8. R. Ding, T. Baehr-Jones, W.-J. Kim et al. J. Lightwave Technol. 29, 8, 11121117 (2011)

9. Alloatti L., Bogaerts W., Dalton L. et al. Journal of Lightwave Technology, 34, 2, 256-268 (2015)

10. Yuqiang Liu, Zhi-Guo Zhang, Zhouhui Xia et al. ACS Nano 10, 1, 704-712 (2016)

11. M. Lira-Cantú, P, Gómez-Romero. Capter 7 in "Hybrid nanocomposites for nanotechnology: electronic, optical, biomedical applications", Ed. Lhadi Merhari (Springer Science+Business Media LLC, 306308, 2009)

12. J.H. Burroughes, D.D.C. Bradley, A.R. Brown, R.N. Marks, K. Mackay, R.H. Friend, P.L. Burns and A.B. Holmes, Nature 347, 539 (1990)

13. B.W. D'Andrade, M.A. Baldo, C. Adachi, J. Brooks, M.E. Thompson and S.R. Forrest, Applied Physics Letters 79, 1045 (2001)

14. T. van Woudenbergh, J. Wildeman, P.W.M. Blom, J.J.A.M. Bastiaansen and B.M.W. Langeveld-Voss, Advanced Functional Materials 14, 677 (2004).

15. R.W.J. de Boer, M.E. Gershenson, A.F. Morpurgo, V. Podzorov, Phys. stat. sol. (a) 201, 1302 (2004)

16. S. Scheinert and G. Paasch, Phys. stat. sol. (a) 201, 1263 (2004)

17. A. Goetzberger, C. Hebling, H.W. Schook, Mater. Sci. Eng. R40, 1 (2003)

18. S.E. Shaheen, D.S. Ginley and G.E. Jabbour, MRS Bulletin 30, 10 (2005)

19. D.J. Milliron, I. Gur, A.P. Alivisator, MRS Bulletin 30, 41 (2005)

20. H. Hoppe, N.S. Sariciftci, J. Mater. Chem. 16, 45 (2006)

21. J.C. Hindson, Z. Saghi, J.-C. Garrido Hernandez, P.A. Midgley, N.C. Greenham, Nano Lett. 11, 2, 904-909 (2011)

22. T.Ya. Gorbach, P.S. Smertenko, S.V. Svechnikov, M. Kuzma, Thin Solid Films 511-512, 494 (2006)
23. R. Ciach, Yu.P. Dotsenko, V.V. Naumov, A.N. Shmyryeva, P.S. Smertenko, Solar Energy Materials \& Solar Cells 76, 4, 613 (2003)

24. P. Smertenko, L. Fenenko, L. Brehmer and S. Schrader, Advantages in Colloid and Interface Science 116, 255 (2005)

25. T.Ya. Gorbach, R.Yu. Holiney, L.A. Matveeva, P.S. Smertenko, S.V. Svechnikov, E.F. Venger, R. Ciach, M. Faryna, Thin Solid Films 336, 63 (1998).

26. M. Lampert, P. Mark, Current Injection in Solids, Academic Press, New York \& London, 1970

27. A. N. Zyuganov, S. V. Svechnikov. Contact-injection phenomena in semiconductors (Naukova dumka, Kyiv, 1981)

28. S. M. Sze, Physics of semiconductor devices (New York, Chichester, Brisbane, Toronto, Singapore, 1981)

29. M. Pope, Ch.E. Swenberg, Electronic Processes in Organic Crystals and Polymers, second edition (New York, Oxford, Oxford University Press, 1999)

30. N.A. Davidenko, L.I. Fenenko, A.A. Ishtchenko, M. Kuzma, P.S. Smertenko, S.V. Svechnikov, Synthetic Metals 122, 173 (2001) 